\title{
ENTOMOLOGY
}

\section{Knock down and insecticidal activity of the plants Tagetes minuta, Lippia javanica, Lantana camara, Tagetes erecta and Eucalyptus grandis on Anopheles arabiensis mosquitoes}

\author{
N. Lukwa, ${ }^{1}$ T. Mduluza, ${ }^{2}$ C. Nyoni, ${ }^{3}$ A.T. Lukwa, ${ }^{4}$ M. Zimba ${ }^{5}$ \\ ${ }^{1}$ National Institute of Health Research, Harare, Zimbabwe; ${ }^{2}$ Department of Biochemistry, University of Zimbabwe, \\ Harare, Zimbabwe; ${ }^{3}$ Department of Social Work, Bindura University of Science Education, Bindura, Zimbabwe; \\ ${ }^{4}$ Faculty of Health Sciences, School of Public Health and Family Medicine, Health Economics Unit, University of \\ Cape Town, South Africa; ${ }^{5}$ Department of Biological Sciences, University of Zimbabwe, Department of Biological \\ Sciences, Harare, Zimbabwe
}

\begin{abstract}
The knock down and insecticidal effects of the plants Tagetes minuta, Lippia javanica, Lantana camara, Tagetes erecta and Eucalyptus grandis were evaluated against Anopheles arabiensis mosquitoes in thatched round huts in Mumurwi village. Leaves from these plants were smouldered in order to provide mosquito
\end{abstract}

Correspondence: Nzira Lukwa, National Institute of Health Research, P. O. Box CY573, Causeway, Harare, Zimbabwe.

E-mail:nziraa33@yahoo.co.uk

Key words: Repellence, mosquito, plants, knock down, insecticidal, mortality.

Acknowledgements: We would like to acknowledge the householders who offered their houses to be used for research.

Contributions: NL designed the study, carried out research, wrote the paper, and submitted it for publication. TM designed the study, wrote the paper and analysed data. $\mathrm{CN}$ reviewed the paper and analysed data. ATL analysed data and reviewed the paper. MZ wrote the paper and analysed data.

Conflict of interest: the authors declare no potential conflict of interest.

Funding: none.

Received for publication: 18 December 2017.

Revision received: 13 November 2018.

Accepted for publication: 13 November 2018.

CCopyright N. Lukwa et al., 2018

Licensee PAGEPress, Italy

Journal of Entomological and Acarological Research 2018; 50:7241 doi:10.4081/jear.2018.7241

This article is distributed under the terms of the Creative Commons Attribution Noncommercial License (by-nc 4.0) which permits any noncommercial use, distribution, and reproduction in any medium, provided the original author(s) and source are credited. repellent smoke. Complete knock down was provided 40 minutes after mosquitoes were exposed to smoke of $T$. erecta, 60 minutes to smoke of $T$. minuta and E. grandis and 120 minutes to smoke of $L$. javanica. Complete knock down of mosquitoes could not be provided by $L$. camara within the 140-minute exposure period. The $\mathrm{KT}_{50}$ (time required to knock down $50 \%$ of the mosquitoes) values were 24.985 minutes ( $T$. minuta), 34.473 minutes (T. erecta), 59.119 minutes (L. javanica), 59.828 minutes (L. camara) and 25.245 minutes (E. grandis). The $\mathrm{KT}_{90}$ (time required to knock down $90 \%$ of the mosquitoes) values were 48.060 minutes $(T$. minuta), 50.169 minutes (T. erecta), 178.341 minutes (L. javanica), 140.220 minutes (L. camara) and 47.998 minutes (E. grandis). Mortality rates $24 \mathrm{~h}$ after exposure were $40 \%$ (T. minuta), $100 \%$ (T. erecta), 75\% (L. javanica), 90\% (L. camara) and 100\% (E. grandis). In conclusion, smoke from the plants $T$. erecta, $T$. minuta and $E$. grandis had very fast knock down rates with $T$. erecta, L. camara and E. grandis killing over $90 \%$ of the An. arabiensis mosquitoes. Plant smoke is important in mosquito control.

\section{Introduction}

Mosquitoes have been associated with painful bites, nuisance and disease transmission in many parts of the world. Some mosquitoes are vectors of malaria, filariasis and arboviruses (dengue, West Nile, Zika) and females from some mosquito species bite both humans and animals (Pavela \& Benelli, 2016). Prevention of mosquito bites is the key strategy in Integrated Vector Management (IVM) and comes at a cost, depending on the strategy used. Use of commercial repellents has a direct cost that most poor people cannot usually afford in some countries, including those in Africa. Several studies documented different uses of mosquito repellents such as production of smoke by smoldering plants (Vernede et al., 1994), hanging up plants (Dube et al., 2011), application of plant oils and juices on the skin (Pavela \& Benelli, 2016) and other methods used at local level. Some plants have insecticidal effect and eventually kill mosquitoes whereas others just ward off mosquitoes. Tabari et al., (2017) noted that some botanically based plants can provide eco-friendly vector control programs against mosquito vectors. 
Ethnobotanical research documented use of plants and some researchers have gone further to validate claims associated with plant use. Validation of ethnobotanical plant extracts helps preserve effective plant species and discourage use of non-effective ones. Some validation processes have rendered useless some plants that were perceived to have mosquito repellent properties (Lalthazuali, 2017).

Moore and Lenglet (2004) proposed that the smoke from plants may disguise human kairomone cues used by mosquitoes to target their hosts or disrupt convectional currents responsible for location, and/or burnt leaves may release volatile compounds that repel or irritate mosquitoes. A study conducted by Paru et al., (1995) in Papua New Guinea showed that wood smoke reduced Anopheline and Culicine biting by $79 \%$. Deletre et al., (2013) tested the efficacy of 20 plants on Anopheles gambiae adult mosquitoes and the following plants did not exhibit pronounced mortality $(\geq 50 \%)$ when applied at $1 \%$ concentration; eucalyptus, pennyroyal, pepper, dill, ginger, neem, geranium, lemon, soldage, lemongrass, itsea, aframomum, colous, coriander and cumin. However, the following plants caused pronounced mortality on An. gambiae adult mosquitoes; citronella $(88.6 \%)$, savory $(87.3 \%)$ and thyme $(87.9 \%)$.

The $\mathrm{KT}_{50}$ (Knock down Time for $50 \%$ of An. gambiae) was recorded when plants were used at $1 \%$ concentration and the results were 1.2 (Cymbopogon citrus, 33.5 (Cymbopogon giganteus), 49.9 (Cymbopogon schoenanthus), 32.2 (Eucalyptus citriodora), 25.2 (Eucalyptus tereticornis), 8.1 (Cochlospermuum tinctorium), 20.9 (Cochlospermuum planchonii), 76.2 (Securidaca longepedunnculata) and 110.9 (Chenopodium ambrosiodes) (Bossou et al., 2013). The $\mathrm{KT}_{90}$ (Knock down Time for $90 \%$ of $A n$. gambiae) when plants were used at $1 \%$ concentration was $6.6(C y$. citrus), 100.2 (Cy. giganteus), 117.8 (Cy. schoenanthus), 61.7 (E. citriodora, 16.1 (E. tereticornis), 16.7 (C. tinctorium, 39.9 (C. planchonii), 91.3 (S. longepedunnculata) and 178.9 (C. ambrosiodes) (Bossou et al., 2013).

The mortality rate when An. gambiae were used was $100 \%$ (Cy. citrus), 29.6\% (Cy. giganteus), 6.7\% (Cy. schoenanthus) $75.5 \%$ (E. citriodora), 98\% (E. tereticornis), 72.7\% (C. tinctorium), 24.5\% (C. planchonii), 8.6\% (S. longepedunnculata) and 41.9\% (C. ambrosiodes) (Bossou et al., 2013). All adult Aedes aegypti mosquitoes died when exposed for 120 minutes to Lippia origanoides that was used at $300 \mathrm{ppm}$ (parts per million) (Castillo et al., 2017). The study by Soonwera et al., (2015) showed that the essential oil of Cananga odorata flowers knocked down $96 \%$ of Ae. aegypti mosquitoes as compared with $98.4 \%$ (Anopheles dirus) and $100 \%$ (Culex quinquefasciatus) mosquitoes. Plants have been shown to have repellent, knock down and insecticidal effect. Repellency alone is beneficial, but the ability to kill mosquitoes is a very big advantage.

The knock down and insecticidal effects of the plants Tagetes minuta (Mexican marigold), Lippia javanica (fever tea), Lantana camara (cherry pie), Tagetes erecta (African marigold) and Eucalyptus grandis (gum tree) were tested against Anopheles arabiensis mosquitoes in Mumurwi village, Bindura district, Zimbabwe.

\section{Materials and Methods}

The leaves of the plants T. minuta, L. javanica, L. camara, E. grandis and $T$. erecta were collected from Mumurwi village $\left(17^{\circ} 31^{\prime} \mathrm{S}-22^{\circ} 31^{\prime} \mathrm{E}\right)$, Bindura district, Mashonaland Central province, Zimbabwe.

\section{Plant reparations}

After the leaves were collected, they were kept for 1 week at room temperature $\left(26^{\circ} \mathrm{C}\right)$ for them to dry before grinding them to powder. A total of 1 kilogramme of eaves of each plant species was ground to powder using a pestle and mortar. Each plant species was kept separately in 1L jars away from sunlight until use.

\section{Preparation of huts}

A total of 6 grass thatched round huts used as kitchens were identified from Mumurwi village. Each hut had not been sprayed before using residual insecticides for malaria control. A smouldering fire using the same type of wood was smouldered in each of the 6 huts at the centre of the hut as traditionally done at the fire place. The round huts had wall heights measuring 1.98-2.1 metres with house diameters ranging 3.25-4.20 metres.

\section{Knock down effect}

A total of 20 female An. arabiensis mosquitoes were placed in each paper cup measuring $10.8 \mathrm{~cm}$ (height), $7 \mathrm{~cm}$ (top rim diameter) and $4.7 \mathrm{~cm}$ (bottom rim diameter) and there were 5 paper cups for each treatment. The capacity of the paper cup was $250 \mathrm{ml}$. The mosquitoes were acclimatized for 1 hour before use.

A total of 50 grams of powdered leaves of each plant species was placed in a metal tin that was placed on a smouldering fire in each of the selected thatched round huts. The control hut had the same conditions apart from the repellent plant. The mosquitoes that were knocked down in each paper cup were counted every 10 minutes for 140 minutes. The time required to knock down $50 \%$ $\left(\mathrm{KT}_{50}\right)$ and $90 \%\left(\mathrm{KT}_{90}\right)$ of the mosquitoes was determined using the Environmental Protection Agency (EPA) Probit Analysis programme used for calculating LC/EC (lethal concentration/effective concentration) values, Version 1.5. This method was previously described by Finney, (1952).

\section{Insecticidal effect}

All the mosquitoes that were used for the determination of knock down effect were provided with cotton swabs dipped in $10 \%$ sugar solution and eventually kept for 24 hours before scoring mortality.

\section{Data analysis}

The data was entered in an EXCEL sheet and analysed using ANOVA (Analysis of variance) method. Significant differences were determined at $95 \%$ confidence limit.

\section{Results}

\section{Knock down effect}

The smoke from T. erecta, T. minuta and E. grandis knocked down $100 \%$ of the An. arabiensis mosquitoes within the 140 minute exposure time (Table 1). The smoke of L. javanica knocked down $100 \%$ of the mosquitoes 120 minutes post exposure but this efficacy was then lost. L. camara failed to knock down $100 \%$ of the An. arabiensis mosquitoes within 140 minutes. The mean knock down rate of An. arabiensis mosquitoes by $T$. erecta was higher than that by T. minuta although the results were not significantly different at $95 \%$ confidence limit $(\mathrm{P}=0.76)$. T. minuta knocked down more mosquitoes than $L$. javanica and the results were significantly different $(\mathrm{P}=0.93)$. E. grandis knocked down more mosquitoes than T. minuta although the results were not significantly different $(\mathrm{P}=0.99)$. E. grandis knocked down more mos- 
quitoes than $L$. camara and the results were significantly different $(\mathrm{P}=0.028)$. T. minuta knocked down more mosquitoes than $L$. camara and the results were significantly different $(\mathrm{P}=0.027)$. The knock down rate of mosquitoes by $L$. javanica and $L$. camara were of the same magnitude and the results were not significantly different $(\mathrm{P}=0.93)$. All plants knocked down more mosquitoes than the control and the results were significantly different $\left(\mathrm{P}=1.35 \times 10^{-10}\right)$.

The plant T. minuta had the fastest $\mathrm{KT}_{50}$ followed by E. grandis, T. erecta and L. javanica (Figure 1). The fastest $\mathrm{KT}_{90}$ was in this order: T. minuta, E. grandis, T. erecta, L. camara and L. javan$i c a$. Plants with fast knock down rate offer better protection from active mosquito biting than those with long knock down rates.

\section{Insecticidal effect of smoke}

One hundred percent mortality of An. arabiensis mosquitoes was recorded with smoke from $T$. erecta and E. grandis (Table 2).
T. minuta killed $<50 \%$ of An. arabiensis mosquitoes as compared with L. javanica and L. camara.

\section{Discussions and Conclusions}

\section{Knock down effect}

Smoke generated by repellent plants has been used to repel mosquitoes and insects. The knock down effect is one of the elements important in mosquito repellence since it shows, not only the ability to minimize mosquito human contact, but the potential to completely deactivate the biting possibility. In this study, the knock down effect of plants on mosquitoes increased with increasing time of exposure where $T$. erecta, T. minuta and E. grandis showed fast knock down on An. arabiensis mosquitoes. The ability

Table 1. The effect of smoke from plants in knocking down An. arabiensis mosquitoes (absolute numbers with \% knock down indicated in brackets).

\begin{tabular}{|c|c|c|c|c|c|c|}
\hline Minutes for exposure & T. erecta $(\%)$ & T. minuta (\%) & L. javanica (\%) & L. camara $(\%)$ & E. grandis $(\%)$ & Control (\%) \\
\hline 10 & $10(10)$ & $0(0)$ & $0(0)$ & $0(0)$ & $0(0)$ & $0(0)$ \\
\hline 20 & $40(40)$ & $32(32)$ & $10(10)$ & $0(0)$ & $30(30)$ & $0(0)$ \\
\hline 30 & $69(69)$ & $70(70)$ & $30(30)$ & $0(0)$ & $70(70)$ & $0(0)$ \\
\hline 40 & $100(100)$ & $76(76)$ & $10(10)$ & $30(30)$ & $78(78)$ & $0(0)$ \\
\hline 50 & $100(100)$ & $93(93)$ & $50(50)$ & $10(10)$ & $92(92)$ & $0(0)$ \\
\hline 60 & $100(100)$ & $100(100)$ & $50(50)$ & $50(50)$ & $100(100)$ & $1(10)$ \\
\hline 70 & $100(100)$ & $100(100)$ & $80(80)$ & $79(79)$ & $100(100)$ & $1(10)$ \\
\hline 80 & $100(100)$ & $100(100)$ & $41(41)$ & $79(79)$ & $100(100)$ & $1(10)$ \\
\hline 90 & $100(100)$ & $100(100)$ & $70(70)$ & $79(79)$ & $100(100)$ & $1(10)$ \\
\hline 100 & $100(100)$ & $100(100)$ & $79(79)$ & $82(82)$ & $100(100)$ & $1(10)$ \\
\hline 110 & $100(100)$ & $100(100)$ & $81(81)$ & $88(88)$ & $100(100)$ & $1(10)$ \\
\hline 120 & $100(100)$ & $100(100)$ & $100(100)$ & $89(89)$ & $100(100)$ & $1(10)$ \\
\hline 130 & $100(100)$ & $100(100)$ & $88(88)$ & $73(73)$ & $100(100)$ & $1(10)$ \\
\hline 140 & $100(100)$ & $100(100)$ & $75(75)$ & $89(89)$ & $100(100)$ & $1(10)$ \\
\hline Mean & $87.1 \pm 28.2^{\mathrm{a}}$ & $83.6 \pm 30.9^{a}$ & $54.6 \pm 32.3^{\mathrm{b}}$ & $53.4 \pm 37.1^{\mathrm{b}}$ & $83.6 \pm 31.1^{\mathrm{a}}$ & $6.46 \pm 4.9 c$ \\
\hline
\end{tabular}

The same letter in the same row means denotes no significant difference, different letter in the same row denotes significance difference.

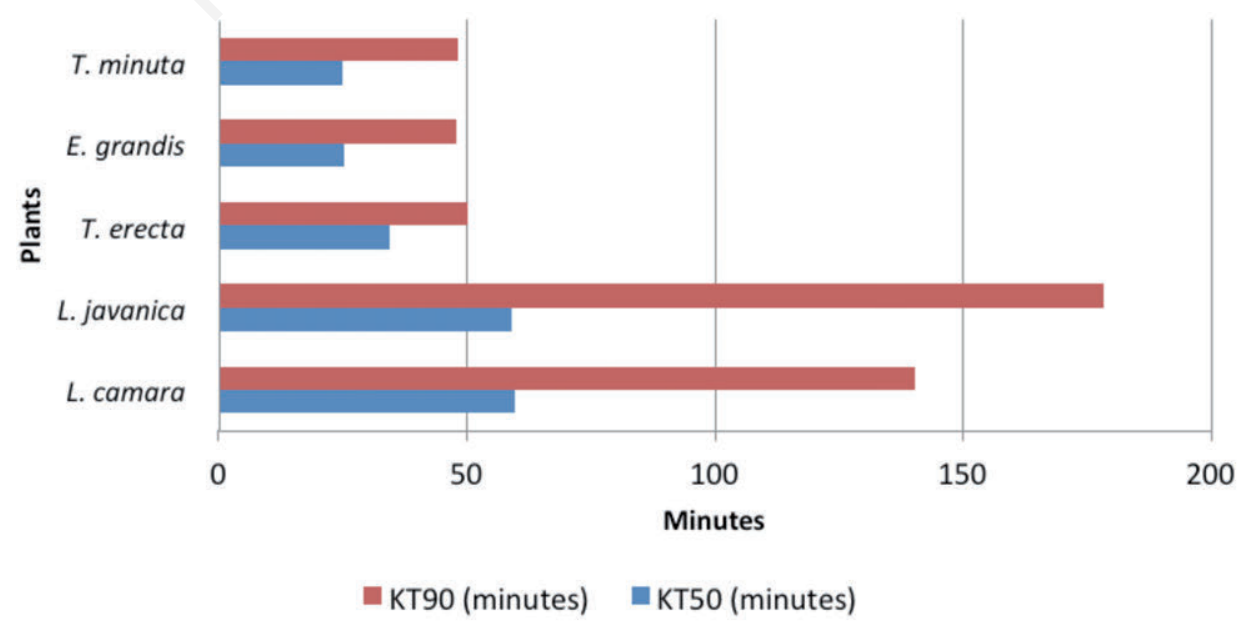

Figure 1. Comparison of KT50 and KT90 values on An. arabiensis due to plant smoke. 
of a plant based repellent to knock down mosquitoes fast is advantageous in that the number of mosquitoes taking a full blood meal and inflicting painful bites is minimized, thus having an effect in disease transmission.

It is worth noting that $T$. erecta had the fastest knock down effect (less minutes) whereby L. javanica took 3 times more than T. erecta. On the other hand, E. grandis and T. minuta took half the time to knock down $100 \%$ of the mosquitoes than L. javanica. Our results agree with other experimental researches, where smoke from burning vegetation or wood in Papua Nuova Guinea (Vernede et al., 1994) and smoke from burning plants in South Africa (Mavundza et al., 2011) were used for protection against mosquito biting. The study in Papua New Guinea showed that wood smoke reduced Anopheline and Culicine biting by $79 \%$ and this might be the case in our study were plants with fast knock down effect were found (Paru et al., 1995).

Absence of complete knock down of An. arabiensis mosquitoes due to smoke from $L$. camara might be related to the exposure time. Exposure times more than 140 minutes might have either improved results or it might be that the plant $L$. camara reached its saturation peak and no further knock down could be recorded. Some element of reversal of mosquito knock down was experienced with L. javanica 130 minutes after exposure. Reversal of knock down has implications since this can increase the number of mosquitoes biting humans. Our results on $100 \%$ knock down of $T$. erecta, T. minuta and L. javanica compared well with those on $C$. odorata (Cx. quinquefasciatus) but better than C. odorata on Ae. aegypti and An. dirus by Soonwera et al., (2015)

All plants in this study did not show very good $\mathrm{K}_{\mathrm{T} 50}$ like those observed with Cy. citrus, C. tinctorium and C. planchonii (Bossou et al., 2013). However, the $\mathrm{K}_{\mathrm{T} 50}$ values of $T$. erecta were comparable to Cy. giganteus and E. citriodora (Bossou et al., 2013). The $\mathrm{K}_{\mathrm{T} 50}$ values of $T$. minuta and E. grandis were comparable to E. tereticornis (Bossou et al., 2013). The $\mathrm{K}_{\mathrm{T} 50}$ values of $L$. javanica and $L$. camara were higher than those of Cy. giganteus (Bossou et al., 2013). Results on the $\mathrm{K}_{\mathrm{T} 50}$ values of all our plants were better than those of S. longepedunnculata and C. ambrosiodes (Bossou et al., 2013).

In terms of $\mathrm{K}_{\mathrm{T} 90}$ values, E. grandis offered the fastest knock down rate, followed by $T$. erecta, then $L$. camara and lastly $L$. javanica. Plants with high knock down rates may be useful in minimizing human mosquito contact and therefore reduce mosquito nuisance. Such a scenario may improve the availability of peaceful nights by inhabitants with limited mosquito biting. These results indicate that plants may be used at a small scale in areas where these repellents are locally available.

\section{Insecticidal effect}

The insecticidal effect of smoke generated by the plants $T$. erecta and E. grandis were well pronounced, killing $100 \%$ of the

Table 2. Number of dead mosquitoes $24 \mathrm{hrs}$ after exposure to plant smoke.

\begin{tabular}{lc} 
Plant repellent & 24hr mortality of An. arabiensis (\%) \\
T. minuta & $40 / 100(40)$ \\
T. erecta & $100 / 100(100)$ \\
\hline L. javanica & $75 / 100(75)$ \\
L. camara & $90 / 100(90)$ \\
E. grandis & $100 / 100(100)$ \\
Control & $0 / 100(0)$ \\
\hline
\end{tabular}

An. arabiensis mosquitoes $24 \mathrm{hrs}$ after exposure and these results were better than those on citronella, savory and thyme (Paru et al., 1995). Our results on $100 \%$ mortality were also better than those on Cy. giganteus, Cy. schoenanthus, E. citriodora, E. tereticornis, C. tinctorium, C. planchonii, S. longepedunnculata and C. ambrosiodes (Bossou et al., 2013). Our results on $100 \%$ mortality of An. arabiensis exposed to $T$. erecta and $E$. grandis agree with findings by Castillo et al., 2017 on. L. origanoides .Such an observation may indicate a reduction in vector density to a limited scale and therefore making available very few mosquitoes for disease transmission. The fast knock down rates caused by $T$. erecta and $E$. grandis will be an added advantage when coupled with the high mortality rates as well. However, smoke from the plant $T$. minuta failed to kill a substantial number of An. arabiensis mosquitoes despite the high knock down rate experienced and these results are slightly higher than those recorded by Paru et al., (1995) on An. gambiae mosquitoes. The high knock down rate of the plant may be an advantage, since when knocked down mosquitoes fall on the floor; they can be picked up by scavengers and are eventually eliminated. The plants $L$. javanica and L. camara exhibited moderate insecticidal effect that may be useful in the prevention of insect biting, in agreement with findings by Liverani et al., (2017). Smoke generated by repellent plants might be useful in situations where commercial mosquito coils may be out of reach, taking into account that insect repellents are used at a large scale in countries like Mexico (Kuri-Morales et al., 2017). Our results may open up avenues for further research in the provision of alternative sources of mosquito repellents (Islam et al., 2017).

Plants used as mosquito repellents have shown time dependent activity on the knock down effect when their resultant smoke was assayed in village huts. The maximum exposure period of 140 minutes appeared to be ideal for $60 \%$ of the plants and there might be need to increase this time in order to take into account plants with slow knock down activity. In conclusion, smoke from the plants $T$. erecta, $T$. minuta and $E$. grandis had very fast knock down rates with $T$. erecta, L. camara and E. grandis killing over $90 \%$ of the An. arabiensis mosquitoes. Validation of the knock down and insecticidal effect of the plants $T$. erecta, T. minuta, E. grandis, $L$. camara and L. javanica has shown some promising results on their effect on An. arabiensis as noted by Lalthazuali et al., (2017).

\section{References}

BOSSOU A.D., MANGELINCKX S., YEDOMONHAN H., BOKO P.M., AKOGBETO M.C., DE KIMPE N., AVLESSI F. AND SOHOUNHLOUE D., 2013 - Chemical composition and insecticidal activity of plant essential oils from Benin against Anopheles gambiae (Giles) - Parasit. Vectors 3: 337.

CASTILLO R.M., STASHENKO E. AND DUQUE J.E., 2017 Insecticidal and repellent activity of several plant-derived essential oils against Aedes aegypti - J. Am. Mosq. Control. Assoc. 33: 25-35.

DELETRE E., MARTIN T., CAMPAGNE P., BOURGUET D., CADIN A., MENUT C., DUBE F.F., TADESSE K., BIRGERSSON G., SEYOUM E., TEKIE H., IGNELL R., HILL S.R., 2011 - Fresh, dried or smoked? Repellent properties of volatiles emitted from ethnomedicinal plant leaves against malaria and yellow fever vectors in Ethiopia .Malar. J. 19: 375.

FINNEY D.J., 1952 - Probit Analysis. Cambridge, Cambridge University Press.

ISLAM J., ZAMAN K., TYAGI V., DUARAH S., DHIMAN S. AND CHATTOPADHYAY P., 2017 - Protection against mos- 
quito vectors Aedes aegypti, Anopheles stephensi and Culex quinquefasciatus using a novel insect repellent, ethyl anthranilate. - Acta Trop. 174: 56-63.

KURI-MORALES P.A., CORREA-MORALES F., GONZALEZACOSTA C., SANCHEZ-TEJEDA G., MORENO-GARCIA M., DAVALOS-BECERRIL E., JUAREZ-FRANCO M.F., BENITEZ-ALVA J.I., GONZALEZ-ROLDAN J.F., 2017 Repellency of 29 synthetic and natural commercial topical insect repellents against Aedes aegypti (Diptera: Culicidae) in Central Mexico. - J. Med. Entomol. 54: 1305-1311.

LALTHAZUALI M.N., 2017- Mosquito repellent activity of volatile oils from selected aromatic plants. - Parasitol. Res. 116: 821-825.

LIVERANI M., CHARLWOOD J.D., LAWFORD H., YEUNG S., 2017 - Field assessment of a novel spatial repellent for malaria control: a feasibility and acceptability study in Mondulkiri, Cambodia - Mal. J. 16: 412.

MAVUNDZA E.J., MAHARAJ R., FINNIE J.F., KABERA G., VAN STADEN J., 2011 - An ethnobotanical survey of mosquito repellent plants in uMkhanyakude district, KwaZulu-Natal province, South Africa - J. Ethnopharmacol. 137: 1516-20.

MOORE S.J., LENGLET A.D., 2004 - An overview of plants used for insect repellents In: Traditional Medicinal Plants and
Malaria. Wilcox M, Bodeker G, Rasoanaivo P, editor. London: CRC Press, Taylor and Francis: 344-363.

PARU R., HII J., LEWIS D., ALPERS M.P., 1995 - Relative repellency of woodsmoke and topical applications of plant products against mosquitoes - Papua New Guinea Med. J. 38: 215-221.

PAVELA R. AND BENELLI G., 2016 - Ethnobotanical knowledge on botanical repellents employed in the African region against mosquito vectors - A review - Exp. Parasitol. 167: 103-108.

SOONWERA M., 2015 - Efficacy of essential oil from Cananga odorata (Lamk.) Hook.f. \& Thomson (Annonaceae) against three mosquito species Aedes aegypti (L.), Anopheles dirus (Peyton and Harrison), and Culex quinquefasciatus (Say) Parasitol. Res. 114: 4531-43.

TABARI M.A., YOUSSEFI M.R., ESFANDIARI A., BENELLI G., 2017 - Toxicity of $\beta$-citronellol, geraniol and linalool from Pelargonium roseum essential oil against the West Nile and filariasis vector Culex pipiens (Diptera: Culicidae) - Res. Vet. Sci. 114:36-40.

VERNEDE R., VAN MEER M.M., ALPERS M.P., 1994 - Smoke as a form of personal protection against mosquitos, a field study in Papua New Guinea - Southeast. Asian J. Trop. Med. Publ. Health 25: 771-775. 